\title{
Contraceptive Trends and Preferred Methods among Users in Port Harcourt, Niger Delta Region of Nigeria
}

\author{
John Dimkpa Ojule*, Dagogo Semenitari Abam \\ Department of Obstetrics and Gynaecology, University of Port Harcourt Teaching Hospital, Port Harcourt, Nigeria \\ Email: *ojulejohn@yahoo.com
}

How to cite this paper: Ojule, J.D. and Abam, D.S. (2017) Contraceptive Trends and Preferred Methods among Users in Port Harcourt, Niger Delta Region of Nigeria. Journal of Biosciences and Medicines, 5, 97-107.

https://doi.org/10.4236/jbm.2017.58008

Received: July 12, 2017

Accepted: August 15, 2017

Published: August 18, 2017

Copyright $\odot 2017$ by authors and Scientific Research Publishing Inc. This work is licensed under the Creative Commons Attribution International License (CC BY 4.0).

http://creativecommons.org/licenses/by/4.0/

\begin{abstract}
Background: Family planning has clearly been a major public health success as evidenced by substantial fertility decline and reductions in maternal mortality in countries with high contraceptive prevalence rates. Nigerian governments have continued to expand the scope and improve accessibility and availability of contraceptive commodities to improve uptake, giving the numerous benefits. Objective: To determine the trends in contraceptive usage and the preferred method among clients visiting the family planning clinic of University of Port Harcourt Teaching Hospital (UPTH), Nigeria. Method: It was a cross sectional study of all clients who accepted contraceptive methods at the UPTH, between $1^{\text {st }}$ January 2000 and $31^{\text {st }}$ December, 2015. Results: During the period, a total of 9190 clients accepted contraceptive methods, and 40,334 women were delivered in the maternity unit giving an acceptance rate of 1 in 4 deliveries or $22.8 \%$. The acceptors of modern contraceptives increased steadily from 491 clients in 2001 to a peak in 2008 with 1477 clients and sharply declined to 381 in 2009 before increasing gradually again to 519 clients in 2015. The most commonly used method was the male condom by 3194 clients (37.9\%), followed by injectables, which was accepted by 2185 clients (23.8\%) while 1752 clients (19.1\%) used the IUD. Implant contraceptive was used by 915 clients $(9.9 \%)$, followed by oral contraceptive pills used by 547 (6.0\%). Female sterilization was the least commonly used method by 302 clients (3.3\%). There was no vasectomy over the 15 years period. Conclusion: Contraceptive trend in Port Harcourt has an ambivalent acceptance pattern. Although male condom and injectable contraceptives are the most commonly used method over time, the subdermal implants are increasingly becoming very popular in recent time. Female sterilization remains the least common method with no record of vasectomy.
\end{abstract}




\section{Keywords}

Contraceptive Methods, Contraception, Trends, Port Harcourt, Niger Delta, Nigeria

\section{Introduction}

Contraception, sometimes used interchangeably with family planning, is the voluntary prevention of pregnancy through the interruption of the sequence of events that leads to conception, while family planning on the other hand refers to the planning, provision and use of birth control [1], to postpone, space or limit childbirth by individuals and couples.

Although contraception has been practiced since the ancient times, effective and safe methods of family planning became available in the $20^{\text {th }}$ century [2]. The availability and use of modern and safer birth control methods has far reaching implications for our health and wellbeing as well as potential benefits to individuals, families and the society at large.

The benefits include improved health, economic and social outcomes for women and families as well as positive impacts on the public and environmental health [3].

By spacing pregnancy through lengthening of inter-pregnancy interval, family planning allows women time to recover and replenish their bodies, improving their health status, delivery outcomes and thus leading to reduction in maternal and perinatal morbidity and mortality [3] [4] [5].

By decelerating population growth as well, women have more earning potential. This enables families to allocate more resources to each child, resulting in poverty reduction, better and happier society [5] [6]. Additionally, family planning can potentially prevent unwanted pregnancies and therefore unsafe abortions and its sequelae, human immunodeficiency virus transmission and acquired immune deficiency syndrome and other sexually transmissible diseases [7].

However, despite these numerous benefits, access to family planning even when clearly indicated or needed, is discouraged or limited due to cultural, moral, religious, political and economic reasons especially in developing countries like Nigeria [4]. The unmet need for family planning is therefore still reportedly high at an estimated 222 million worldwide, disproportionately higher in developing nations [8] [9].

Meeting this need would probably prevent over 53 million unintended pregnancies including 26 million abortions especially in resource limited countries with restrictive abortion laws [9].

Nigeria with a contraceptive prevalence rate of $15 \%$ [10] had one of the worlds' highest maternal mortality ratio of 1000-1500/100,000 live births [11], with illegal and unsafe abortions contributing $20 \%-40 \%$ of the 60,000 maternal 
deaths recorded annually [12] [13]. Contraceptive prevalence rates no doubt have direct relationship with maternal mortality indices. It has been robustly shown that nations with low contraceptive prevalence rates have high maternal mortality ratios [14]. Effective and widespread family planning would prevent unwanted pregnancies, abortion related complications and maternal deaths [14].

Leveraging on the numerous benefits of contraception, the Nigerian government in 1989 established a family planning policy within the primary health care frame work [15], aimed at improving access, availability and affordability of contraceptive commodities to all parts of the country. The effort expectedly should have positive impact; improve the contraceptive uptake and the embarrassing maternal health indices in Nigeria.

Port Harcourt, the capital city of Rivers state has for decades been the nerve centre of oil and gas prospecting and refining activities with influx of all classes of people of different ethnic extractions from within and without the state and can be described as a microcosm of Nigeria with an estimated population of over 5 million people.

The family planning clinic of the University of Port Harcourt teaching hospital (UPTH), Port Harcourt draws its clients from the multi-ethnic and the indigenous population residing in Port Harcourt and the extended catchment states of Niger Delta region of Nigeria.

Evaluating the trend in contraception and preferred method among users has enabled us provide updates on the contraceptive service delivery in Port Harcourt and assess the impact of the sustained efforts of the successive government in Nigeria aimed at increasing the contraceptive uptake rate.

\section{Materials and Methods}

The UPTH is an 800-bed tertiary hospital, providing all levels of health service delivery in Port Harcourt, Rivers state. It has 4 major clinical departments: Internal medicine, Paediatrics, Surgery and Obstetrics and Gynaecology and allied clinical departments.

The Obstetrics and Gynaecology $(\mathrm{O} \& \mathrm{G})$ department operates the antenatal, the post-natal, Gynaecological and the family planning clinics which all run weekly from Monday to Friday. It also has labour wards and operating theatres located within the labour ward complex which offers 24 -hour services, with an average annual delivery rate of 2500 .

The family planning clinic is located within the Obstetrics and Gynaecology Complex. It has at present 4 consultant family planning physicians, 3 family planning nurse practitioners, rotating resident doctors, trainee nurses and other supporting staff. The family planning clinic runs from 8 am to $4 \mathrm{pm}$ on week days, and consults an average 15 clients a day.

The various contraceptive methods available in the UPTH include the Oral contraceptive pills (progestogen only pill and the combined oral contraceptive pills), the injectable contraceptives (combined injectable and progestogen only 
contraceptives), implants (Implanon and Jadelle), Intra uterine device (copper T-380A), the barrier contraceptives (male and female condoms, cervical caps, diaphragms and foam tablets and bilateral tubal ligation.

The clients are usually referred from the post-natal and general out-patient clinics of UPTH as well as clients from Health centres and private hospitals from within and outside Port Harcourt and members of the general public and some students of the University of Port Harcourt.

At the clinic, each client is counselled on the various methods, emphasizing the benefits, side effects and contraindications of each method and guided to choose an appropriate contraceptive suitable for the client.

A full medical history is taken and physical examination performed and relevant investigations done. The client is then given the chosen method. Those who opt for bilateral tubal ligation usually have the surgery performed in the operating theatres by the consultants. The clients are then given appointments at the family planning clinic.

At each return visit, all the complaints volunteered by the clients are documented and thereafter clinically re-assessed. A client is considered lost to follow-up if she defaults for 2 or more scheduled visits.

Ethical clearance for the study was given by the UPTH Ethics and Research Committee.

It was a-15 year cross-sectional retrospective study of all clients who accepted contraceptive methods at the family planning clinic of the University of Port Harcourt Teaching Hospital, southern Nigeria, between $1^{\text {st }}$ January 2001 and $31^{\text {st }}$ December, 2015.

The total number of each contraceptive method used by the clients for each year was retrieved from the record section of the family planning clinic. Also the total number of deliveries for each year was retrieved from the maternity registers of the department.

The data obtained were entered into Excel spread sheet which was also used for analysis and results expressed in figures and simple percentages.

\section{Results}

During the study period, a total of 9190 clients accepted contraceptive methods and there were 40,334 deliveries in our maternity unit, giving an acceptance rate 1 in 4 deliveries or $22.8 \%$.

The methods used were the oral contraceptive pills, injectable contraceptives, implants, intra uterine device, male condoms and bilateral tubal ligation.

The condom was the most common method used by 3194 clients representing $37.9 \%$, followed by the injectable contraceptives used by 2185 clients constituting $23.8 \%$ while the least method of choice was the female sterilization accepted by $302(3.3 \%)$ clients as shown in Table 1.

The acceptors of the various methods increased steadily over the years from a total of 491 clients in the year 2001 to a peak in the year 2008 with a total of 1477 
Table 1. Total contribution of each method over the study period.

\begin{tabular}{ccc}
\hline Method & Number & Percentage \\
\hline BTL & 302 & $3.3 \%$ \\
OCP & 547 & $6.0 \%$ \\
Implants & 915 & $9.9 \%$ \\
IUD & 1752 & $19.1 \%$ \\
Injectables & 2185 & $23.8 \%$ \\
Condoms & 3194 & $37.9 \%$ \\
Total & 9190 & $100 \%$ \\
\hline
\end{tabular}

BTL- Bilateral tubal ligation; OCP- Oral contraceptive pills; IUD- Intra uterine device.

Table 2. Yearly trends in acceptance of the various contraceptive methods.

\begin{tabular}{|c|c|c|c|c|c|c|c|}
\hline \multirow{2}{*}{ Year } & \multicolumn{7}{|c|}{ Method } \\
\hline & OCP (\%) & Injectable (\%) & Implant (\%) & IUD (\%) & Condom (\%) & BTL (\%) & Total (\%) \\
\hline 2001 & $67(13.6)$ & $229(46.6)$ & $4(0.8)$ & $99(20.2)$ & $69(14.1)$ & $23(4.7)$ & $491(100)$ \\
\hline 2002 & $42(7.7)$ & $278(51.5)$ & $9(1.7)$ & $173(32.0)$ & $16(3.0)$ & $22(4.1)$ & $540(100)$ \\
\hline 2003 & $61(11.1)$ & $185(33.7)$ & $14(2.5)$ & $226(41.2)$ & $34(6.2)$ & $29(5.3)$ & $549(100)$ \\
\hline 2004 & $130(17.6)$ & $251(34.1)$ & $0(0)$ & $232(31.5)$ & $93(12.6)$ & $31(4.2)$ & $737(100)$ \\
\hline 2005 & $123(21.1)$ & $227(39.0)$ & $0(0)$ & $136(23.3)$ & $83(14.2)$ & $14(2.4)$ & $583(100)$ \\
\hline 2006 & $49(9.1)$ & $257(48.0)$ & $2(0.4)$ & $151(28.2)$ & $77(14.3)$ & $0(0)$ & $536(100)$ \\
\hline 2007 & $28(3.0)$ & $149(15.8)$ & $22(2.3)$ & $83(8.8)$ & $641(67.8)$ & $22(2.3)$ & $945(100)$ \\
\hline 2008 & $23(1.6)$ & $131(8.8)$ & $92(6.2)$ & $76(5.2)$ & $1125(76.2)$ & $30(2.0)$ & $1477(100)$ \\
\hline 2009 & $6(1.6)$ & $109(28.6)$ & $65(17.1)$ & $72(18.9)$ & $112(29.4)$ & $17(4.4)$ & $381(100)$ \\
\hline 2010 & $7(1.6)$ & $101(22.9)$ & $65(14.7)$ & $121(27.4)$ & $137(31.1)$ & $10(2.3)$ & $441(100)$ \\
\hline 2011 & $2(0.4)$ & $98(20.7)$ & $101(21.3)$ & $104(21.9)$ & $143(30.2)$ & $26(5.5)$ & $474(100)$ \\
\hline 2012 & $2(0.4)$ & $69(14.6)$ & 97 (20.6) & 69 (14.6) & $220(46.6)$ & $15(3.2)$ & $472(100)$ \\
\hline 2013 & $3(0.5)$ & $48(7.2)$ & 93 (13.9) & $75(11.2)$ & $428(64.1)$ & $21(3.1)$ & $668(100)$ \\
\hline 2014 & $2(0.5)$ & $12(3.2)$ & $141(37.4)$ & $64(17)$ & $156(41.4)$ & $2(0.5)$ & $377(100)$ \\
\hline 2015 & $2(0.4)$ & $41(7.9)$ & $210(40.4)$ & 71 (13.7) & $155(29.9)$ & $40(7.7)$ & $519(100)$ \\
\hline Total & $547(6.0)$ & $2185(23.8)$ & 915 (9.9) & $1752(19.0)$ & $3489(38.0)$ & $302(3.3)$ & $9190(100)$ \\
\hline
\end{tabular}

clients, and thereafter decreased to 377 in the year 2014 with just 377 clients but followed by a sudden rise to 519 clients in 2015 at the end of the observation period, as shown in Table 2. The oral contraceptive pills had its highest number of acceptors in the year 2004 with 130 clients thereafter had a steep and steadily declined to just 2 acceptors in 2015, making a total contribution of 547 (6.0\%) acceptors at the end of the study period. The implants increased from 4 clients in 2001 to 14 in 2003 when Norplant use was discontinued in our centre. When the newer subdermal contraceptive implant (Jadelle and Implanon) use was introduced in our FPC in 2006, its acceptance increased gradually from 2 clients to 210 acceptors in 2015 representing the most common contraceptive method of choice that year at $40 \%$. The IUD made its maximum contribution of 232 ac- 
Table 3. Yearly trend in contraceptive acceptance rate.

\begin{tabular}{cccc}
\hline Year & no. of acceptors & no. of deliveries & Acceptance rate (percentage) \\
\hline 2001 & 491 & 1761 & $27.9 \%$ \\
2002 & 540 & 2291 & $23.6 \%$ \\
2003 & 549 & 2828 & $19.4 \%$ \\
2004 & 737 & 2925 & $25.2 \%$ \\
2005 & 583 & 2652 & $22.0 \%$ \\
2006 & 536 & 3137 & $17.1 \%$ \\
2007 & 945 & 2744 & $34.4 \%$ \\
2008 & 1477 & 3374 & $43.8 \%$ \\
2009 & 381 & 3176 & $12.0 \%$ \\
2010 & 441 & 3025 & $14.6 \%$ \\
2011 & 474 & 3660 & $13.0 \%$ \\
2012 & 472 & 3413 & $13.8 \%$ \\
2013 & 668 & 2515 & $26.6 \%$ \\
2014 & 377 & 1095 & $34.4 \%$ \\
2015 & 519 & 1738 & $30.0 \%$ \\
Total & 9190 & 40,334 & $22.8 \%$ \\
\hline
\end{tabular}

Acceptance rate $=9190 / 40,334 \times 100 \%=22.8 \%$.

ceptors to the contraceptive mix in the 2004 but thereafter steadily declined to 71 acceptors in 2015.

The highest contraceptive acceptance rate of $43.8 \%$ was in the year 2008 when there was 1477 acceptors of modern contraception with 3374 women delivering in the maternity unit. This was immediately followed by the lowest acceptance rate of $12.0 \%$ the following year with gradual increase in the subsequent years up to $30.0 \%$ in the final year of the study in 2015 , as illustrated in Table 3 .

\section{Discussion}

While contraceptive use has increased steadily over the years in developed countries of the world, uptake rate has remained disproportionately low in Subsaharan Africa, including Nigeria [16].

Concerted efforts of successive Nigerian governments aimed at improving contraceptive awareness and uptake has not commensurately translated to higher utilization rate as evidenced by the current national contraceptive prevalence rate of $15 \%$ [10]. This is further corroborated by the acceptance rate of $22.8 \%$ documented in this study, similar to the $20 \%$ uptake rate reported in Port Harcourt previously [17], but at variance with the 31.6\% reported from Kano, North-western Nigeria [18] and $13.8 \%$ reported from Ilorin, North-central Nigeria [19].

The reasons for the low contraceptive utilization have been ascribed to the inability to effectively dismantle the barriers to family planning at the national, regional, community, institutional, family and individual levels in our environ- 
ment [20]. These include forbidding use of certain methods in a region or religious groups, denying certain methods to certain groups-single, adolescent or nulliparous women and clients discontinuation as a result of husbands disapproval [20].

Male condom acceptance gradually increased to reach a peak at the middle of the study period and maintained a consistent lead to remain the most commonly accepted method at $37.9 \%$ at the end of the observation period, which is at variance with an earlier report from Port Harcourt [17], and findings elsewhere [18] [19].

The very low condom use rate reported from the previous studies [17], was probably because data was collated only from married couples practicing contraception. Other researchers have reported condom use to be very low at $2 \%$ $6 \%$ among married women in developing countries [18], and declining globally in the past decades [21], ranking near the bottom among contraceptives used by married people [22]. This is not surprising because many men especially in west Africa believe that condom use is only appropriate with casual sex partners or girl friends but not with their wives [23]. Also, for married women, requesting an intimate partner to use condom suggests lack of trust [23], because condom use in our environment is associated with illicit sex and infidelity and consequently has suffered an image problem [24].

The UPTH moved from the temporary site at the old Port Harcourt town to its permanent site in Alakahia in October 2006, just adjacent the University of Port Harcourt. Since the family planning clinic (FPC) of UPTH is open to all regardless of marital status or sex the teeming student population of the university probably took advantage of this to source condoms from the clinic, in keeping with the finding that most of the need for condoms is among sexually active unmarried youths [19].

With the devastating global HIV pandemic, the condom has since been identified as the only contraceptive method that can both prevent pregnancy and HIV and other STIs and much of the need for condom use is to prevent these [18]. The federal, state, local governments, Non-Governmental Organisations (NGOs) and various professional organisations in Nigeria have made tremendous efforts to discourage unprotected sexual intercourse by promoting condom use especially among the teeming youths and singles, and encourage mutual fidelity in Marriages to stem the rising HIV and STD epidemic in Nigeria. These will explain the reasons for the predominance of condom use in UPTH family planning clinic in this study.

The injectable contraceptive contributed $23.8 \%$ to the contraceptive mix, just behind the condom. In previous studies in Port Harcourt [17] [25], injectable contraceptives was the most commonly used birth control method in keeping with findings elsewhere [19] [26] [27]. It is also the most common method of family planning in Nigeria [10].

The earlier studies were conducted when UPTH was in the temporary site 
with little or no students patronage of the family planning clinic.

The IUD made its greatest contribution to the contraceptive mix in the earlier years to rank the $3^{\text {rd }}$ most commonly accepted method at $19.1 \%$ at the conclusion of the study. This may be due to the introduction of the newer contraceptive implants in 2006 after norplant withdrawal in our centre and the rapidly increasing acceptance and preference of this over other methods of contraception by our clients [28].

Similarly, the OCP made its modest contribution at the initial phase of the study but thereafter rapidly declined making an overall contribution of $6.0 \%$. This declining trend appears rather surprising because OCP is reported to be one of the most commonly used methods of fertility control worldwide [29]. This rapidly declining patronage of OCP and the reasons for the decline has recently been documented in our centre [30].

Although, implant contraceptive was the $4^{\text {th }}$ commonly used method at $9.9 \%$ acceptance rate, its uptake gradually increased from its re-introduction in 2006 to becoming the most popular method in the final year of the study. The increasing popularity of implants in our centre may be due its very high efficacy, long acting nature with much less frequent return hospital visits and has earlier been reported in a previous study [28].

Bilateral tubal ligation was the least method of contraception used in this study. Aversion to sterilization has previously been reported in our environment [18]. The reasons for this include cost, socio-cultural beliefs, its permanent nature and high premium placed on child birth in our environment [18].

Expectedly, there was no record of vasectomy in this study, in keeping with findings of other researchers that male sterilization is virtually non-existent in Sub-saharan Africa [31]. The barriers to this include misconception, fears, socio-cultural reasons, inadequate information and male dominance [23].

There was no stable pattern in contraceptive acceptance rate over the years in Port Harcourt. This may be due to service disruptions occasioned by industrial actions by the various labour unions. The Nigeria labour congress (NLC), the Nigeria Medical Association, (NMA), the National Association of Resident Doctors (NARD), Joint Health Sector Union (JOHESU) and their affiliate including state chapters and local branches in various government agencies and parastatals frequently embark on strike actions leading to partial or total service withdrawals in the hospitals. There were service disruptions at least once every year during the period. There were industrial actions by the UPTH Resident doctors in May, June and October 2001, while the nurses embarked on strike action in July the same year. Similarly, other Health workers Union went on strike in December of that same year. Again UPTH resident doctors embarked on industrial action between $1^{\text {st }}$ January to $11^{\text {th }}$ March, 2002..This was the trend over the years, resulting in the loss of over 525 working days to industrial actions during the 15 years period of observation. Service disruptions were particularly worst off between 2009 and 2012 resulting in very low acceptance rates during 
those years. These were responsible for the unstable contraceptive trend.

The retrospective nature and the inherent problems of data loss and incomplete records are some of the limitations of this study. A prospective study has the potential of correcting this document lapses and improve the study.

\section{Conclusion}

Contraceptive trend in Port Harcourt has an ambivalent acceptance pattern. Although male condom and injectable contraceptives are the most commonly used method over time, the subdermal contraceptive implants are increasingly becoming very popular in the recent time. Female sterilization remains the least common method with no record of vasectomy. Concerted efforts should continue to be made by the various levels of governments in Nigeria to continue to expand the scope, availability, accessibility and affordability of contraceptive commodities in all parts of Nigeria especially the rural areas with abysmally low contraceptive prevalence. Sustained education of the masses on the importance and benefits of family planning is hereby strongly advocated to improve awareness and dispel the myths about family planning using the mass media, social media, drama presentations and town hall meetings. Capacity building by training and re-training of staff is also important to provide a robust man powerbase of family planning service providers.

\section{Conflict of Interest}

The authors declare no conflict of interest.

\section{Funding}

The study was funded by the authors.

\section{References}

[1] Oxford English Dictionary (2017) Oxford University Press, Oxford.

[2] Hansen, S.J. and Burke, A.E. (2010) Fertility Control: Contraception, Sterilization and Abortion. In: Hurt, K.J., Guile, M.W., Bienstock, J.L., Fox, H.E. and Wallach, E.E., Eds., The Johns Hopkins Manual of Gynaecology and Obstetrics, 4th Edition, Wolters Kluwer Health/Lippincott Williams \& Wilkins, Philadelphia, 382-395.

[3] Cleland, J., Conde-Agudelo, A., Peterson, H., Ross, J. and Tsui, A. (2012) Contraception and Health. The Lancet, 380, 149-159. https://doi.org/10.1016/S0140-6736(12)60609-6

[4] Ahmed, S., Li, Q., Liu, L. and Tsui, A.O. (2012) Maternal Deaths Averted by Contraceptive Use: An Analysis of 172 Countries. The Lancet, 380, 111-125. https://doi.org/10.1016/S0140-6736(12)60478-4

[5] Canning, D. and Schultz, T.P. (2012) The Economic Consequences of Reproductive Health and Family Planning. The Lancet, 380, 165-171. https://doi.org/10.1016/S0140-6736(12)60827-7

[6] Van Braeckel, D., Temmerman, M., Roelens, K. and Degomme, O. (2012) Slowing Population Growth for Wellbeing and Development. The Lancet, 380, 84-85. 
https://doi.org/10.1016/S0140-6736(12)60902-7

[7] World Health Organistion (WHO) (2013) Family Planning Facts Sheet. World Health Organistion, Geneva.

[8] Singh, S. and Darroch, J.E. (2012) Adding It Up: Costs and Benefits of Contraceptives-Estimates for 2012. Guttmacher Institute and United Nations Population Fund, New York.

[9] Carr, B., Gates, M.F., Mitchell, A. and Shah, R. (2012) Giving Women the Power to Plan Their Families. The Lancet, 380, 80-82.

https://doi.org/10.1016/S0140-6736(12)60905-2

[10] National Population Commission (Nigeria) and ICF International (2014) Nigeria Demographic and Health Survey 2013. National Population Commission and ICF International, Rockville, Maryland.

[11] World Health Organisation (WHO) (2005) Maternal Mortality Ratio in 2005: Estimates by UNICEF, WHO, UNFPA, World Bank. WHO, Geneva.

[12] Oriji, V.K., Jeremiah, I. and Kasso, T. (2009) Induced Abortion amongst Undergraduate of University of Port Harcourt. Nigerian Journal of Medicine, 18, 199-202. https://doi.org/10.4314/njm.v18i2.45065

[13] Oye-Adeniran, B.A., Adewole, I.F., Umoh, V.A., et al. (2004) Community Based Survey of Unwanted Pregnancies in Southwestern Nigeria. African Journal of Reproductive Health, 8, 103-115. https://doi.org/10.2307/3583397

[14] Stover, J. and Ross, J. (2010) How Increased Contraceptive Use Has Reduced Maternal Mortality. Maternal and Child Health Journal, 14, 687-695. https://doi.org/10.1007/s10995-009-0505-y

[15] Ujah, I., Uguru, V.E., Aisien, A.O., Sagay, A.S. and Otubu, J.A.M. (1999) How Is Safe Motherhood in Nigeria? The Trend of Maternal Mortality in a Tertiary Health Institution. East African Medical Journal, 76, 434-437.

[16] Shane, K., Mishra, V., Arnold, F. and Abderrahm, N. (2007) Contraceptive Trends in Developing Countries. DHS Contraceptive Reports No. 16. Macro International Inc., Calverton, Maryland.

[17] Ojule, J.D. and Macpepple, D.A. (2011) Family Planning Practice in a Tertiary Health Institution in Southern Nigeria. West African Journal of Medicine, 30, 178181.

[18] Muhammad, Z. and Maimuna, D.G. (2014) Contraceptive Trend in a Tertiary Facility in Northwestern Nigeria: A 10 Year Review. Nigerian Journal of Basic and Clinical Sciences, 11, 99-103. https://doi.org/10.4103/0331-8540.140358

[19] Idowu, O.A. and Munirdeen, A.I. (2010) Recent Trend in Pattern of Contraceptive use at a Nigeria Tertiary Hospital. Journal of Clinical Medicine Research, 2, 180 184.

[20] World Health Organisation (WHO): Maternal and Newborn Health (2003) The role of Family Planning. Report of a Regional Consultation, Chiang Mai, 19-21 November 2003, WHO Project: ICP MPS 001.

[21] Ozumba, B.C., Obi, S.N. and Ijeoma, N.N. (2005) Knowledge, Attitude and Practice of Modern Contraception among Single Women in Southeast Nigeria. Journal of Obstetrics and Gynaecology, 25, 295-305. ttps://doi.org/10.1080/01443610500105498

[22] Orji, E.O. and Onwudiegwu, U. (2002) Prevalence and Determinant of Contraceptive Practice in a Defined Nigerian Population. Journal of Obstetrics and Gynaecology, 22, 540-543. https://doi.org/10.1080/0144361021000003126 
[23] Iliyasu, Z., Mandara, M.U. and Mande, A.T. (2004) Community Leaders Perspective of Reproductive Health Issues and Programmes in Northern Nigeria. Tropical Journal of Obstetrics and Gynaecology, 2, 83-87.

[24] Keele, J.J., Forste, R. and Flake, D.F. (2005) Hearing Native Voices: Contraceptive Use in Matnwe Village, East Africa. African Journal of Reproductive Health, 9, 32 41. https://doi.org/10.2307/3583158

[25] Ojule, J.D., Oriji, V.K. and Okongwu, C. (2010) A Five Year Review of Complications of Progestogen-Only Injectable Contraceptives at the University of Port Harcourt Teaching Hospital. Nigerian Journal of Medicine, 19, 87-95. https://doi.org/10.4314/njm.v19i1.52487

[26] Ameh, N. and Sule, T. (2007) Contraceptive Choices among Women in Zaria, Nigeria. Nigerian Journal of Clinical Practice, 10, 203-207.

[27] Ojiyi, E. and Dike, E. (2009) The Choice of Contraceptives among Women in Orlu, Nigeria. Port Harcourt Medical Journal, 4, 63-67.

[28] Ojule, J.D., Oranu, E.O. and Enyindah, C.E. (2012) Experience with Implanon in Southern Nigeria. JMMS, 3, 710-714.

[29] Gallo, M.F., Grimmes, D.A. and Schulz, K.F. (2004) Combination Estrogen-Progestin Contraceptives and Body Weight. Systematic Review of Randomised Control Trials. Obstetrics and Gynaecology, 103, 359-373. https://doi.org/10.1097/01.AOG.0000107298.29343.6a

[30] Ojule, J.D. and Oranu, E.O. (2017) Combined Oral Contraceptive Use at the University of Port Harcourt Teaching Hospital, Port Harcourt, Southern Nigeria. The Journal of Bioscience and Medicine, 5, 7-17. https://doi.org/10.4236/jbm.2017.56002

[31] Robey, B., Zlidar, V.M., Morris, L., Gardner, R., Rustein, S.O. and Goldberg, H. (2003) The Reproductive Revolution Continues: New Survey Findings. Population reports, Series M,N 17. John Hopkins School of public Health, Population Information Program, Baltimore.

Scientific Research Publishing

Submit or recommend next manuscript to SCIRP and we will provide best service for you:

Accepting pre-submission inquiries through Email, Facebook, LinkedIn, Twitter, etc. A wide selection of journals (inclusive of 9 subjects, more than 200 journals)

Providing 24-hour high-quality service

User-friendly online submission system

Fair and swift peer-review system

Efficient typesetting and proofreading procedure

Display of the result of downloads and visits, as well as the number of cited articles

Maximum dissemination of your research work

Submit your manuscript at: http://papersubmission.scirp.org/

Or contact jbm@scirp.org 